\title{
LA ENSEÑANZA DE LA HISTORIA DE LA PSICOLOGIA EN LAS UNIVERSIDADES PARAGUAYAS
}

\author{
TEACHING THE HISTORY OF PSYCHOLOGY IN THE UNIVERSITY PARAGUAY
}

\author{
José E. García N ${ }^{1}$ \\ Universidad Católica, Asunción, Paraguay. \\ (RECIBIDO EL 15/10/2011, ACEPTADO EL 15/12/ 2011)
}

\begin{abstract}
RESUMEN
En el Paraguay la enseñanza de la historia de la psicología se inicia con el establecimiento de la primera carrera en la década de 1960, en la Universidad Católica de Asunción. Aquélla primera cátedra se denominó Historia de los sistemas psicológicos y estuvo a cargo del sacerdote jesuita uruguayo Carlos Mullin. Las cátedras iniciales eran cursos de historia general de la psicología y conferían escasa atención a la psicología latinoamericana y paraguaya. El estudio organizado de esta última comenzó con la realización de un curso regular de Historia de la Psicología en la Universidad Católica de Ciudad del Este (1994) que recogía contenidos y autores pertenecientes a la psicología nacional. En el 2004 se organizó un seminario en la Universidad del Norte de Asunción denominado Introducción a la Psicología Paraguaya que incluyó un segmento especial denominado Historia de la Psicología en Paraguay. Este artículo describe en forma cronológica la enseñanza de la historia de la psicología en el Paraguay como disciplina de contenido específico en los programas de psicología. A fin de organizar mejor los conceptos se hace una diferencia entre los cursos de historia general de la psicología que comprenden contenidos diferenciales de psicología paraguaya y las cátedras cuya atención se dirige propiamente a la psicología en el Paraguay como contenido troncal. También se discuten las características generales de estos cursos así como los ejes temáticos para su enseñanza, los puntos estudiados en ellos y otros aspectos relacionados, además de su pertinencia para la formación del psicólogo en el Paraguay.
\end{abstract}

Palabras clave: Historia de la Psicología, Enseñanza de la Psicología, Psicología en Paraguay, Psicología latinoamericana, Formación del psicólogo.

\begin{abstract}
In Paraguay the teaching of the history of psychology began with the foundation of the first psychological department in the decade of 1960 at the Catholic University in Asunción. That first course were named History of psychological systems and the professor was the uruguayan jesuit priest Carlos Mullin. The first experiences were courses of general history of psychology that paid little attention to both the latin american and the paraguayan psychologies. The organized study of this last one began with the regular course in the

1 Docente de la Universidad Católica de Asunción, Paraguay E-maill: joseemiliogarcia@hotmail.com
\end{abstract}


History of Psychology at the Catholic University in Ciudad del Este (1994) that gathered particular information concerning the paraguayan national psychology. In 2004 a seminary named Introduction to Paraguayan Psychology was organized at the University of the North in Asunción, including a special segment on the History of Psychology in Paraguay. This article describes in chronology the teaching of the history of psychology in the country as a matter of specific contents on psychology study programs. In this paper a clear difference between the general courses in the history of psychology that comprises special contents on paraguayan psychology and the courses oriented toward psychology in Paraguay as its main academic content is proposed. The article also discusses both the general characteristics of these courses and the thematic axis for their teaching, the contents for the study of the field and other aspects, as well as its relevancy for the training of psychologist in Paraguay.

Key words: History of Psychology, Teaching of Psychology, Psychology in Paraguay, Latin american psychology, Training of psychologists.

\section{INTRODUCCION}

Los cambios en la estructura y contenido que conciernen a la enseñanza de la historia de la psicología en un país específico no pueden disociarse por completo de la evolución que experimenta el conjunto de la psicología en el país mencionado. No puede ser de otra manera puesto que esta historia, en lo que atañe a su sentido más elemental, se refiere a las modificaciones que surgen en la comprensión social de los objetos, ya sean tangibles o conceptuales, cuya naturaleza es reconocida como psicológica. Por ello la historia de la psicología tiene como su campo de estudio a toda la serie de transformaciones que han modelado a la ciencia psicológica en su largo peregrinar desde los orígenes en la reflexión filosófica antigua hasta las alternativas científicas y profesionales que emergen en el presente. En muchos casos la psicología también puede estudiarse de forma más delimitada en referencia a una nación, una región geográfica o un continente entero o bien enfocarse hacia la indagación de los cambios ocurridos en campos concretos de investigación o de aplicación así como en la formación paulatina de las teorías psicológicas. Cuando este último sentido es el elegido se destacan la identidad de los fundadores, las condiciones de origen y los tópicos preferidos para la reflexión, conceptualización o investigación dentro de los límites admitidos por el enfoque en particular del que se trate. Aquí son de especial importancia las variantes de contenido y perspectiva que van surgiendo al interior de las diferentes teorías, mini teorías, escuelas o modelos psicológicos tal y como discurren en su desarrollo a lo largo del tiempo.

\section{METODO}

Dentro de este amplio horizonte el estudio de las psicologías nacionales y de sus procesos modeladores a nivel histórico es un componente muy importante. En cierto sentido, una buena parte de la historia de la psicología, al menos en la forma que se la presenta en los textos contemporáneos para su estudio universitario, es en realidad la historia de la psicología en un solo país, principalmente de los Estados Unidos y en alguna medida de unas pocas naciones europeas como Francia, Austria, Rusia, Inglaterra o Suiza, que han tenido una predominancia mayor porque 
en ellas surgieron algunos de sus mentores principales y las teorizaciones más influyentes. Frente a este panorama, la investigación sobre el desarrollo histórico de la psicología en otros países más alejados del centro, y especialmente en las naciones de América Latina, aparece como mucho menos relevante o significativo, concitando una atención menor. La búsqueda de los orígenes y el avance de la psicología en un país específico constituyen una fase previa que llevará más tarde a organizar la enseñanza de la historia de la psicología en esa nación particular. Al mismo tiempo, el esclarecimiento de las alternancias seguidas por la psicología en un solo país tiene el potencial de conducir, a través de una indagación sistemática y ordenada, al descubrimiento de singularidades únicas o de corrientes convergentes con el resto de la psicología tal como se ha modelado y madurado en el resto del continente americano (García, 2011a). Teniendo en cuenta que las sociedades y las culturas difieren entre sí de maneras significativas es razonable suponer que la psicología, aunque sea un producto intelectual importado desde las naciones de mayor desarrollo científico a las de menor gravitación global, deba en algún sentido reflejar esas mismas diferencias que representan la diversidad cultural de las sociedades receptoras, a menos que consideremos como cierta la muy improbable suposición que los psicólogos desempeñan su profesión en un mundillo abstracto y aislado del resto de las tradiciones y los conocimientos sociales. Solo en estas condiciones podría la psicología presumir una absoluta impermeabilidad a las influencias externas.

\section{CONTENIDO}

Este artículo explora algunos aspectos que conciernen al desarrollo de la historia de la psicología en el Paraguay en su faceta de disciplina académica provista de contenido específico, poniendo especial énfasis en la difusión que ha comenzado a verificarse durante la última década respecto a los procesos que caracterizan a esta psicología en su evolución desde los orígenes hasta el tiempo presente. En tal sentido, habrán de considerarse con preferencia tres componentes centrales e interconectados: a) el de la enseñanza de la historia general de la psicología tal como se ha insertado progresivamente en el ámbito universitario, b) el de los primeros intentos por incorporar contenidos particulares referidos a la historia de la psicología en el Paraguay en los cursos de historia general de la disciplina y c) el del diseño y realización de las experiencias iníciales para instalar a la historia de la psicología paraguaya como un ámbito de estudio propio a través del desarrollo de cursos y seminarios en algunas carreras de psicología. En la parte conclusiva del artículo se ensayarán algunas propuestas encaminadas a la mejor organización futura de este campo de estudio.

\section{RESULTADOS}

\section{Orígenes históricos}

La Historia de la Psicología se integró como materia de enseñanza para la formación profesional del psicólogo al quedar habilitados los departamentos que dieron origen 
a la etapa académica y profesional en la primera mitad de la década de 1960. En el curriculum que orientó los estudios de la carrera de psicología en la Universidad Católica de Asunción durante sus años iníciales y cuyas clases comenzaron en marzo de 1963 se incluía un curso cuyo énfasis se hallaba dirigido hacia los cambios en la ciencia psicológica a lo largo de su historia. Esta cátedra, primera en aparecer en orden cronológico, tuvo la denominación de Historia de los sistemas psicológicos. En 1965 y 1966 le fue confiada al sacerdote jesuita uruguayo Carlos Mullin, como parte del entrenamiento básico para los futuros psicólogos. Mullin es una personalidad sobresaliente en los orígenes de la psicología profesional paraguaya. Él fue uno de los fundadores históricos de la carrera en el seno de la Universidad Católica y enseñó otras materias fundamentales como Metodología del trabajo científico, Psicología racional, Psicología de la educación y el aprendizaje y Psicología diferencial. El padre Mullin realizó los estudios que corresponden a la etapa escolar en Montevideo e ingresó a la Compañía de Jesús en 1931. Más tarde cursó las carreras de Filosofía y Teología en la Facultad Pontificia de San Miguel, Argentina, en 1937 y 1944 respectivamente. Se doctoró en Filosofía en la Universidad Católica de Asunción con una tesis cuya defensa en acto público tuvo lugar el 16 de octubre de 1964 (Mullin, 1964) y obtuvo la calificación de cinco felicitado. Pero el padre Mullin estuvo vinculado a la carrera de psicología solo en los primeros años. La revista Dimensión, que por entonces editaba la Facultad de Filosofía y Ciencias de la Educación, informó en su edición de mayo de 1967 que el Dr. Mullin, hasta entonces Secretario General de la facultad y profesor de Psicología durante cuatro años, había partido al Uruguay para ejercer nuevas funciones en el orden académico y administrativo (Anónimo, 1967). Por este motivo las clases de Historia de los sistemas psicológicos fueron encargadas al Dr. Eliseo Sosa Costantini entre los años de 1968 y 1973, que de esta manera pasó a ser su segundo catedrático histórico. Ejerció la medicina y además de sus labores profesionales tuvo la oportunidad de forjar una trayectoria política en las filas del naciente Partido Demócrata Cristiano que comenzó a gestarse en 1960, inicialmente con el nombre de Movimiento Social Cristiano (Colazo, 1993). Sin embargo, solo obtendría su reconocimiento legal en 1989, al caer la dictadura de Alfredo Stroessner (1954-1989). Sosa Costantini fue autor de varios libros de psicología, entre ellos el primero que fuera publicado en el país sobre la reflexología de Pavlov (Sosa Costantini, 1974). La materia que el padre Mullin y el Dr. Sosa Costantini impartieron se transformó en Historia de la Psicología cuando un nuevo plan de estudios comenzó a utilizarse en 1978, con una carga de tres horas semanales de clase. Con esa malla curricular también apareció otra cátedra muy emparentada con la anterior, la de Teorías Psicológicas Contemporáneas, a la que se estableció una carga de cuatro horas por semana.

\section{Desarrollos posteriores}

El abanico de cursos ocupados en la evolución temporal de la psicología consiguió expandirse de manera gradual pero sostenida a partir de entonces. En la actualidad existen cátedras de Historia de la Psicología en las siguientes instituciones: a) la Universidad Nacional de Asunción (UNA), donde la materia se imparte siguiendo 
una modalidad anual en un total de tres secciones distintas que corresponden a su distribución de alumnos en un turno de la tarde y dos en la noche, todas las cuales cuentan con distintos profesores (García, 2010a), b) la Universidad Autónoma del Paraguay (UAP) que está organizada con una extensión anual, c) la Universidad del Cono Sur de las Américas (UCSA) en la que comprende un semestre, d) la Universidad Iberoamericana (UNIBE) que cuenta con dos semestres para «Historia de la Psicología», e) la Universidad Tecnológica Intercontinental (UTIC) en la que alcanza un módulo de su malla curricular, f) la Universidad Politécnica y Artística del Paraguay (UPAP) que también ofrece un módulo único, g) la Universidad Metropolitana de Asunción (UMA) que establece dos semestres dedicados a la historia, h) la Universidad Nacional de Villarrica del Espíritu Santo (UNVES), con sede en la ciudad de Villarrica, y en donde la materia se inserta en el primer semestre de la carrera, i) la Universidad Nacional de Itapúa (UNI), que cuenta con una sede central en la sureña ciudad de Encarnación y filiales en Coronel Bogado y María Auxiliadora, contempla una materia de «Historia de la Psicología» en el primer año de todas sus carreras en el área respectiva y j) la Universidad Nacional de Pilar (UNP), en la que los aspectos históricos de la disciplina son estudiados por los alumnos del primer curso. Como todas las demás universidades estatales -excepción hecha a la UNVES de Villarrica-, la UNI y la UNP también adoptan una estructura de ciclos anuales. Otras instituciones como la Universidad de la Integración de las Américas (UNIDA), que solamente funciona en Asunción, incorporó un curso de «Historia de la Psicología» en el semestre inicial de la carrera, tras una modificación realizada a su malla curricular a principios del 2010, con anterioridad a la cual la materia cubría un par de semestres. No obstante, a comienzos del 2011 esta institución optó por el cierre de su carrera de Psicología. Algunas de las universidades de capital privado mencionadas previamente como la UTIC y la UPAP mantienen en funcionamiento un gran número de filiales en distintas ciudades del país y donde sus respectivas opciones en Psicología reproducen idénticas mallas.

La Universidad Católica (UCA), a la que pertenece la carrera de Psicología más antigua establecida en 1963, realizó varios ajustes en sus planes de estudio desde sus inicios hasta nuestros días. Entre estas modificaciones a su malla curricular, la última tuvo lugar en el 2008. Una de las características del nuevo plan es que suprime el ciclo semestral que se había dedicado por largo tiempo -en verdad, desde la fundación misma de la carrera- al conocimiento de los aspectos históricos de la psicología y formaba parte del anterior esquema de estudios. Por esta razón la cátedra se dictó por última vez durante la segunda mitad del 2008. A lo largo de los últimos veintitrés años, es decir entre 1985 y el 2008, la enseñanza estuvo a cargo del psicólogo Melquiades Alonso. La Universidad Católica no solo ofrece estudios de Psicología en Asunción sino que también habilitó otras carreras en capitales departamentales como Ciudad del Este (UCE), Concepción (UCC), Coronel Oviedo (UC-Coronel Oviedo), Encarnación (UCI) y Villarrica (UCV). La carrera en Ciudad del Este se fundó en 1994, en tanto las de Concepción, Encarnación y Villarrica imparten clases desde el 2004 y la de Coronel Oviedo a partir del 2011. 
Concepción produjo solo dos promociones de psicólogos que comenzaron sus clases en el 2004 y el 2005 y culminaron en 2009 y 2010 respectivamente. Una serie de problemas estructurales condujeron al posterior cierre de la carrera. En Ciudad del Este ingresó una camada nueva de alumnos por última vez en el 2008, sin habilitar nuevos cursos en los tres años siguientes, aunque la carrera formalmente sigue abierta. Las sedes de Coronel Oviedo y Encarnación comenzaron la aplicación del nuevo plan de estudios que actualmente se utiliza en Asunción, la primera en coincidencia con su apertura en el 2011 y la segunda desde el 2010. En esta última coexisten dos grupos de alumnos, uno con el nuevo pensum académico y el otro en usufructo del anterior. La carrera en Ciudad del Este cuenta desde sus inicios con una orientación diferente en su grilla de materias, con un curriculum propio (Rivelli, Lafuente y Lafuente, 1994) que fue concebido para ser aplicado en esa parte del país. En este momento solo la carrera de Villarrica se rige por la malla en uso desde 1978 y por ello habrá de dictar «Historia de la Psicología» por algunos años más, hasta tanto todos los departamentos de la Universidad Católica unifiquen sus planes de estudio conforme a los nuevos lineamentos curriculares.

Igualmente puede mencionarse el caso de algunas instituciones superiores que llegaron a impartir materias centradas en el cruce de la psicología y su historia pero terminaron suprimiéndolas luego, obedeciendo a razones muy diferentes. Por ejemplo la Universidad Americana (UA) de Asunción incluyó brevemente durante la primera mitad del 2005 una materia denominada «Historia de los sistemas psicológicos» que se cursó una sola vez en el tercer semestre de la carrera, aunque luego no haya vuelto a abrirse en los ciclos lectivos posteriores. La Universidad Técnica de Comercialización y Desarrollo (UTCD) que durante los primeros años de implementación en su carrera de Psicología había contemplado un módulo de «Historia de los sistemas» sustituyó luego el énfasis temático principal que definía la materia para convertirla en «Epistemología de la Psicología». Asimismo debe señalarse que, aparte del curso de «Historia de la Psicología», la Universidad Nacional de Asunción cuenta con un área diferenciada de «Historia de los Sistemas Psicológicos» que se imparte en el tercer año de su plan de estudios (García, 2010a). Similares lineamentos comparte la Universidad Nacional de Itapúa cuyo pensum psicológico se basa en una alta proporción en el que aplica la UNA (García, 2011b).

\section{La enseñanza de Historia de la Psicología}

Las oportunidades para dedicar espacios al estudio de la psicología paraguaya en las universidades nacionales, ya sea dentro del programa de las cátedras regulares de historia o con independencia de estas, se pueden describir como sucesos accidentales que al presente resaltan más por su carácter circunstancial y asistemático que por la regularidad. De todos modos, cabe distinguir ciertos eventos en carácter de antecedentes. Las menciones iníciales a temas cuyos contenidos eran alusivos al desarrollo temporal de la psicología en el Paraguay se dieron en el contexto de cursos de Historia de la Psicología entendida en un sentido genérico. Contrariamente a lo que podría esperarse, la primera de ellas no correspondió a una carrera de Psicología ubicada en Asunción sino a un curso en Ciudad del 
Este, una población caracterizada por su gran flujo comercial en la frontera con el Brasil. En ese enclave urbano la sede regional de la Universidad Católica inició en 1994 una carrera de Psicología como parte de su Facultad de Ciencias y Letras, como previamente apuntáramos. Para el año siguiente se dictó por primera vez una cátedra de «Historia de la Psicología». La materia, que ocupaba un semestre del segundo curso, estuvo a cargo del psicólogo José E. García desde 1995 al 2000. El programa abarcaba un total de seis unidades y en la quinta, denominada «La psicología en América Latina», se realizaba un breve repaso sobre la evolución de la psicología en los países de la región, incluyendo Argentina (donde los autores estudiados eran Horacio Piñero, Víctor Mercante, José Ingenieros y Enrique Mouchet), Brasil (destacando sobre todo la figura de Emilio Mira y López), Perú (analizando a Walter Blumenfeld y Honorio Delgado), Chile (donde se hablaba de los primeros laboratorios, de Rómulo Peña Maturana, Guillermo Mann y Guillermo Schneider), Colombia (con menciones a Mercedes Rodrigo) y México (resaltando en este país la figura precursora de Ezequiel A. Chávez). Igualmente se recordaba a otros pioneros europeos emigrados a América Latina como Helena Antipoff, Oliver Brachfeld, Waclaw Radecki y Béla Székely. De estos últimos autores, Székely fue bien conocido entre los primeros estudiantes de psicología paraguayos durante los años sesenta y setenta gracias al uso extensivo que se hizo de su texto sobre los tests psicológicos (Székely, 1966).

En esta unidad programática también se puso énfasis en las aportaciones de mayor originalidad de un cierto número de investigadores en la actual psicología latinoamericana, de modo particular la Síntesis experimental del comportamiento de Rubén Ardila (Ardila, 1997, 2003) y la Etnopsicología de Rogelio Díaz-Guerrero (Alarcón, 2010, Díaz-Guerrero, 1995). A manera de corolario se realizaba un análisis de la psicología en el Paraguay utilizando información proveniente sobre todo de fuentes orales o consultas con textos clásicos, ya que en aquél momento el avance de una historiografía de la psicología paraguaya aún resultaba claramente insuficiente. Para el estudio de la evolución temporal de la disciplina en los demás países de la región se ofrecía una interesante variedad de publicaciones enumeradas en las referencias bibliográficas de la materia (Aguilar y Recinos, 1996, Alarcón, 1980, Ardila, 1986, Díaz-Guerrero, 1995, Hoffman, Tortosa y Carbonell Vaya, 1994, Klappenbach y Pavesi, 1994, León, 1993, 1997, Papini, 1978, 1988, Papini y Mustaca, 1979). La Biblioteca Prof. Dr. Mario Luis de Finis de la Sede Regional en Ciudad del Este aún era muy pequeña por entonces y no disponía de la mayoría de estos recursos bibliográficos -excepción hecha del autorizado texto de referencia de Ardila (1986)- ni tenía organizada una hemeroteca. Por tal motivo, los materiales de lectura eran proveídos directamente por el encargado de la cátedra. Tras el cambio de la titularidad en «Historia de la Psicología» que se produjo en el 2001, aquéllos contenidos que procuraban una disección del pensamiento en la evolución de la psicología nacional terminaron desapareciendo como áreas de estudio.

A pocos años de esta experiencia comenzó a funcionar una carrera de Psicología en la Facultad de Humanidades y Ciencias de la Educación de la Universidad 
Nacional de Pilar (UNP), en la zona sur del país. Pilar es la capital del décimo segundo departamento de Ñeembucú y por su posición geográfica se ubica en la frontera con la Argentina, a pocos kilómetros del punto donde los dos grandes ríos Paraguay y Paraná confluyen en un solo cauce. La carrera de la UNP se inició en 1999 y cuenta con una licenciatura de cinco años estructurada en ciclos anuales, como es frecuente en las universidades del dominio estatal, y con un énfasis terminal en Orientación Educacional. El plan de estudios incorpora una cátedra de «Historia de la Psicología» que se dicta en el primer curso de acuerdo a su esquema de materias. Haciendo un análisis del documento de adecuación curricular que fue preparado para servir como guía a esta carrera (Aguilera, Benítez y González, 1998) y en especial una lectura de los descriptores que se establecen para las diferentes materias de enseñanza, no se observa una mención específica a contenidos que se relacionen con la psicología paraguaya en la sección de este texto oficial que comprende a «Historia de la Psicología». Pero en el programa de cátedra preparado por la psicóloga Cecilia Aguilera, docente de la materia en 1999, se agregaba un punto final en la sexta unidad (denominada genéricamente «La psicología en la actualidad») donde se indicaban dos puntos como parte de un apartado sobre «La Psicología en el Paraguay», a saber: 1) Desarrollo histórico y 2) Antecedentes e investigaciones académicas. Quizá por la escasa disponibilidad de textos que sufría la Universidad de Pilar en los comienzos de su actividad formativa, la bibliografía incluyó únicamente seis libros de los cuales solo uno es un texto de historia de la psicología propiamente dicho, el de Caparrós (1990) que también es señalado como el «texto base». Los otros libros que se mencionan eran cuatro manuales de psicología general y lo completaba uno que incluso se podría considerar algo inusual para un programa de psicología histórica, el conocido Diccionario de Psicología de Friedrich Dorsch, en una de las frecuentes reimpresiones que la Editorial Herder ha realizado del mismo (Dorsch, 1994). Pero no se hace referencia a ninguna fuente que diga relación a la psicología paraguaya, ni tampoco a documentos que puedan apoyar su estudio o investigación, lo que hace pensar que aquél curso se fundamentaba solo en alguna reconstrucción de tipo oral, probablemente muy elemental, cuando en la cátedra se debían hacer referencias a las circunstancias propias que identifican a la psicología de este país.

\section{Otras Experiencias}

Entre los años 2002 y 2003 un seminario sobre Psicología paraguaya en el contexto regional dictado por la psicóloga Diana Lesme en la carrera de Psicología que ofrece la Universidad del Norte de Asunción incluyó conferencias por invitación a cargo del psicólogo José E. García, cuyo énfasis central estuvo dirigido a la evolución de las ideas psicológicas en el Paraguay. Las conferencias se efectuaron el sábado 23 de marzo del 2002 y el jueves 10 de abril del 2003. Entre los años 2004 y 2005 este seminario dio paso a otro denominado Introducción a la Psicología Paraguaya, donde por primera vez se realizó un estudio selectivo de autores, teorías, investigaciones y períodos históricos relacionados a la secuencia temporal que marcó a la psicología en el país. Sobre este curso se ofrecerán detalles adicionales más adelante. Eventos semejantes a los mencionados y que involucraron 
al mismo académico fueron desarrollados en fechas ulteriores. El primero se agendó el miércoles 15 de octubre del 2003 a través de una participación en la cátedra de «Historia de la Psicología» en la Universidad Nacional de Asunción, que por entonces mantenía dos grupos de alumnos en el turno de la noche. La encargada de cátedra en la sección que cursó la invitación era la psicóloga Lenni Wiebe y la intervención estuvo relacionada a un proyecto de investigación de la entonces estudiante Mariana Florentín. Aquél trabajo consistió en la realización de un audiovisual que exploraba los orígenes académicos de la carrera de psicología en el país y recorría de manera gráfica sus escenarios principales. El lunes 14 de noviembre del 2005 tuvo lugar una participación similar con una conferencia para la cátedra de «Historia de la Psicología» de la Universidad Autónoma del Paraguay (UAP), cuya titular hasta este momento es la psicóloga María Angélica de Tone. El viernes 2 de diciembre del mismo año se realizó otra intervención en la cátedra homónima que posee la Universidad Tecnológica Intercontinental (UTIC) cuya sede se encuentra en el municipio de Fernando de la Mora, vecino a Asunción. La docente de esta última era la psicóloga Ariane Haesbaert. Todas estas charlas y conferencias estuvieron focalizadas en una presentación sistemática de la psicología paraguaya enmarcada en una perspectiva cronológica y dirigida de modo particular hacia los autores, las teorías y las publicaciones relevantes.

Es curioso notar cómo la segunda cátedra de «Historia de la Psicología» que asumió una discusión activa sobre autores y procesos referidos a la psicología nacional tampoco haya tenido su epicentro en Asunción, sino en la sureña ciudad de Encarnación, capital del séptimo departamento de Itapúa y enclavada en el límite sur con la Argentina. Precisamente en junio del 2004 comenzó a dictarse una cátedra de «Historia de la Psicología» en la Universidad Nacional de Itapúa (UNI), cuya carrera había comenzado a impartirse ese mismo año como parte de la oferta académica que proponía la Facultad de Humanidades, Ciencias Sociales y Cultura Guaraní. También la Universidad Católica de Itapúa (UCI) y una filial que posee la Universidad Politécnica y Artística del Paraguay (UPAP), que tiene su casa central en Asunción, comenzaron sendas carreras de Psicología dentro del casco urbano de la ciudad durante el mismo año 2004 (García, 2011b). La UNI cuenta con un curriculum de Psicología cuyas materias se dictan en ciclos anuales y donde «Historia de la Psicología» se estudia en el primer curso. La cátedra no tiene su inicio regular en marzo sino en junio de cada año, luego que los alumnos completan un Curso de Ingreso que reviste carácter eliminatorio para todos aquéllos que aspiren alcanzar los estudios superiores, por lo que su duración real es de solo seis meses al año.

La cátedra de la UNI fue otorgada por concurso público al mismo académico que cuatro años antes había organizado el curso que se dictó en la Universidad Católica de Ciudad del Este. Como es previsible, mantuvo similitudes y continuidad de enfoque con aquél en varios de sus planteamientos básicos. También la cátedra de la UNI se hallaba organizada en seis unidades generales distribuidas en un total de veintisiete parágrafos. La quinta de ellas estaba referida a las alternativas de la psicología latinoamericana y paraguaya. El curso de la UNI, a diferencia 
del dictado en Ciudad del Este, gozaba de dos ventajas comparativas sobre su predecesor inmediato: 1) La mayor disponibilidad de literatura de carácter esencialmente histórico a la que ya se podía acceder entre el 2004 y el 2007 -a diferencia de lo ocurrido hasta el 2000- por haber sido publicada en algunos foros de accesibilidad pública como libros y revistas especializadas y 2) El propio avance cualitativo de la investigación historiográfica en el corto lapso de cuatro años que permitía disponer de estudios más detallados y específicos respecto a ideas, teorías, tradiciones intelectuales y autores relevantes. La bibliografía incluida en el curso durante el 2007, último año en que la cátedra fue administrada por el catedrático original, permite comprobar la paulatina acumulación de una creciente literatura de base (García, 2003a, 2003b, 2004, 2005a, 2005b, 2005c, 2006a, 2006b). Al propio tiempo, la organización temática del curso permitía un análisis en mayor detalle sobre los períodos, las ideas psicólogicas imbuídas en los contornos de otras disciplinas colindantes con la psicología como la educación y la sociología, los representantes principales, sus obras, las influencias intelectuales y teóricas, la profesionalización temprana y la evolución general en las áreas de aplicación. En el programa de contenidos de la materia los parágrafos XXIV, XXV y XXVI correspondían en forma particular al análisis de la psicología paraguaya y eran presentados en la siguiente forma:

Tabla 1: La Psicología en Paraguay

\begin{tabular}{|c|c|c|}
\hline I & II & III \\
\hline $\begin{array}{l}\text { El período preuniversitario. } \\
\text { Estudio de sus estadios de } \\
\text { desarrollo. }\end{array}$ & & \\
\hline $\begin{array}{l}\text { Enfoque restringido y } \\
\text { enfoque ampliado. }\end{array}$ & & \\
\hline Los pioneros. & $\begin{array}{l}\text { Los educadores y la } \\
\text { psicología }\end{array}$ & El periodo moderno. \\
\hline $\begin{array}{l}\text { La psicología social: } \\
\text { Sus orígenes }\end{array}$ & $\begin{array}{l}\text { Ramón Indalecio Cardozo } \\
\text { y sus aportes a la Psicología }\end{array}$ & $\begin{array}{l}\text { La psicología en las } \\
\text { universidades }\end{array}$ \\
\hline Cecilio Báez. & Otros autores importantes & La profesión del psicólogo \\
\hline \multicolumn{3}{|l|}{ Ignacio A. Pane } \\
\hline $\begin{array}{l}\text { El carácter nacional según } \\
\text { Manuel Domínguez }\end{array}$ & & \\
\hline
\end{tabular}


Tras el alejamiento de su primer docente, la cátedra de la UNI en los años 2008, 2009, 2010 y 2011 quedó a cargo de la psicóloga Mariela Gaona, quien prosiguió con la línea iniciada con anterioridad y no abandonó el énfasis en la historia de la psicología nacional. Gaona es una de las primeras psicólogas que egresó de los estudios universitarios de psicología que se ofrecieron en la ciudad y fueron iniciados en 1999 (García, 2011b). Pero no solo la UNI prestó atención a la inclusión de contenidos históricos en esta psicología de corte autóctono. También la cátedra de «Historia de la Psicología» de la Universidad Católica de Asunción, a la que nos hemos referido anteriormente y que en la actualidad ya no integra el curriculum en uso por esa institución, incluyó durante los años que la dirigió el psicólogo Melquiades Alonso (1985-2008) la discusión de algunos tópicos históricos que guardan especial relevancia para la psicología paraguaya y que habitualmente tenían cabida en las sesiones finales de cada semestre. El programa elaborado por Alonso comprendía un total de ocho tópicos centrales, a saber:

Tabla 2: Tópicos históricos en debate

\begin{tabular}{l|l}
\hline 01 & El desarrollo de la psicología antes de 1879 \\
\hline 02 & La aplicación del método experimental \\
\hline 03 & Reacciones frente a la «nueva psicología», \\
\hline 04 & La psicología diferencial y la psicometría \\
\hline 05 & La psicología patológica y el método clínico \\
\hline 06 & La psicología y el desarrollo humano \\
\hline 07 & La psicología social \\
\hline 08 & La psicología en el Paraguay \\
\hline
\end{tabular}

La bibliografía no hace mención a fuentes secundarias para el análisis histórico de la psicología paraguaya pero incluye dos de los principales textos que se pueden considerar básicos: a) el primero de los tres volúmenes que componen La Pedagogía de la Escuela Activa del maestro Ramón I. Cardozo (1876-1943), especialmente el segmento de aquél libro que corresponde a una descripción de sus experiencias con la aplicación del test Stanford-Binet en el Paraguay (Cardozo, 1938) y b) el primer capítulo del texto introductorio a la psicología que escribió el también educador Manuel Riquelme (1885-1961) a mediados de la década de 1930 y que se hallaba dedicado a una discusión sobre la naturaleza de la conciencia 
(Riquelme, 1948). Tanto Cardozo como Riquelme han sido reconocidos en varios estudios como dos de los pioneros más sobresalientes de la psicología paraguaya (García, 2003b, 2004, 2005b, 2006b, 2007, 2008a, 2008b, 2009, 2010b, 2011c).

Con anterioridad a 1985 la titularidad de «Historia de la Psicología» había recaído en la psicóloga Manuela Escobar de Peña, en cuyo programa de contenidos no se localiza mención alguna a tópicos que pudieran ser relacionados con la psicología paraguaya. En términos generales la cátedra de «Historia de la Psicología» de la UCA asuncena no produjo investigación sistemática ni publicaciones especializadas desde su creación, tanto de sus profesores como alumnos. Lo que puede mencionarse es una breve elaboración de un trabajo en power point (Alonso, 2007) que fue realizado por el último profesor de la cátedra y cuya finalidad principal era servir como elemento de apoyo para el desarrollo de las clases. El material reúne algunas referencias esquemáticas a hechos y datos históricos que conservan un interés directo para la historia de la psicología nacional. La presentación ponía una atención mayor a la psicología del período moderno, dejando un espacio más modesto a los pioneros de la psicología. De estos se menciona solo a Cardozo, pero no a Riquelme, quien sin embargo también era incluido en el programa de la materia. Pese a su utilidad potencial, este recurso didáctico y de consulta no fue convertido en un artículo razonado que permitiera un desarrollo más extenso $\mathrm{y}$ argumental de las ideas.

\section{La historia de la psicología en el Paraguay}

Tras las cátedras de historia general de la psicología que albergaron tópicos de psicología paraguaya en sus listados de contenido era necesario pasar a un grado de concreción mayor que se dio únicamente con las cursos que enfocaron a la psicología paraguaya de manera particular. El primer seminario que tuvo como su objetivo central el estudio y discusión de la evolución histórica de la psicología paraguaya, en forma específica y no como un apéndice de los estudios sobre la psicología latinoamericana, tuvo lugar en la carrera de Psicología que la Universidad del Norte imparte en Asunción. El antecedente más directo fue un seminario sobre «Psicología en el Paraguay» que estaba a cargo de la psicóloga Diana Lesme. En aquél se discutían los aspectos legales que rigen la profesión del psicólogo en el país así como la vigencia y alcances de los acuerdos vigentes en la unión supranacional del Mercosur en referencia concreta al trabajo de los psicólogos y los protocolos de formación mínima para las universidades de las naciones miembros del bloque, entre otros aspectos importantes. A poco de iniciadas las clases en el seminario original fue haciéndose cada vez más evidente la necesidad de situar en un contexto temporal el análisis de la psicología paraguaya, tomando en consideración sus raíces históricas y apoyando en esta presentación los contenidos centrales del curso, lo cual dio lugar a las primeras conferencias por invitación en los años 2002 y 2003, como fue señalado con anterioridad.

El seminario sobre Introducción a la Psicología Paraguaya se organizó entre marzo del 2004 y septiembre del 2005 con un módulo o segmento inicial dentro de este que se denominó Historia de la Psicología en Paraguay y cuyo manejo 
se hizo con independencia del resto del curso en lo concerniente a los contenidos, la evaluación de los conocimientos y el trabajo didáctico de los profesores. El apartado sobre historia estuvo a cargo del psicólogo José E. García y su contenido programático presentaba un total de trece unidades cuyos ejes básicos eran los siguientes temas y problemas:

Tabla 3: Temas para la historia de la Psicología Paraguaya

\begin{tabular}{|c|c|}
\hline 01 & $\begin{array}{l}\text { Una discusión de contexto sobre los orígenes y desarrollo de la psicología en } \\
\text { América Latina }\end{array}$ \\
\hline 02 & $\begin{array}{l}\text { Las tendencias históricas en la psicología del continente en lo que se refiere } \\
\text { a la producción teórica y científica, poniendo especial atención a los aportes } \\
\text { originales. }\end{array}$ \\
\hline 03 & La periodización de la psicología paraguaya. \\
\hline 04 & $\begin{array}{l}\text { a) Los antecedentes remotos en la teología y la filosofía que imperaban en } \\
\text { tiempos de la colonia. }\end{array}$ \\
\hline 05 & a) El contexto ideológico y filosófico en el que surgió la psicología. \\
\hline 06 & Los primeros autores, sus obras y contenidos respectivos \\
\hline 07 & $\begin{array}{l}\text { El rol que correspondió a las instituciones culturales en la discusión de } \\
\text { la psicología y la promoción de ideas y escritos con temas de contenido } \\
\text { psicológico }\end{array}$ \\
\hline 08 & $\begin{array}{l}\text { Los aportes de las primeras revistas de cultura general como medios que } \\
\text { ayudaron en la difusión temprana de la psicología }\end{array}$ \\
\hline 09 & a) Los estudios pioneros sobre el carácter nacional. \\
\hline 10 & a) Las vinculaciones entre la educación y la psicología. \\
\hline 11 & a) Las relaciones entre la sociología y la psicología social. \\
\hline 12 & $\begin{array}{l}\text { a) El contexto social y cultural específico y sus efectos en el avance o retardo } \\
\text { de la investigación. } \\
\text { 11) Los eventos que se identifican con la profesionalización temprana }\end{array}$ \\
\hline 13 & El surgimiento de las carreras de Psicología \\
\hline 14 & $\begin{array}{l}\text { a) Los orígenes de la psicología aplicada. } \\
\text { ñ) La organización legal de la profesión }\end{array}$ \\
\hline 15 & La expansión de la formación universitaria \\
\hline 16 & La investigación en el período reciente \\
\hline 17 & $\begin{array}{l}\text { a) Los problemas actuales y las perspectivas futuras de la psicología en el } \\
\text { Paraguay. }\end{array}$ \\
\hline
\end{tabular}


En sus aspectos formales, la evaluación del seminario previó la realización de trabajos de investigación por parte de los alumnos cuyos temas se escogían sobre puntos incluidos en el programa o tópicos de importancia colateral y se adoptaban previa aprobación de la cátedra. Los ensayos fueron realizados durante el curso que se impartió en el 2004. La mayoría de estas investigaciones utilizó informaciones publicadas en libros o revistas de psicología, aunque un par de ellas recurrió a fuentes primarias a través de entrevistas y búsqueda en archivos que no eran de acceso público. Las monografías resultantes, aunque básicas y elementales en aspectos como el planteo de sus problemas de investigación y las metodologías utilizadas, sirvieron para conformar un núcleo incipiente de producción historiográfica para la psicología nacional. La lista completa de los trabajos y sus respectivos autores se ofrecen en el anexo número 1, mientras el programa de contenidos que abarcó el seminario aparece en el anexo número 2. Las monografías cubrieron una variedad importante de puntos tanto del período preuniversitario de la psicología nacional como de la etapa más reciente de la formación universitaria, incluyendo:

1) Historia de la psicología latinoamericana: 2 trabajos.

2) Los orígenes de la psicología en el Paraguay: 1 trabajo.

3) La psicología del indígena: 1 trabajo.

4) El hipnotismo de Diógenes Decoud: 1 trabajo.

5) La Revista del Instituto Paraguayo: 1 trabajo.

6) Las obras de Cecilio Báez y Ramón Indalecio Cardozo: 1 trabajo.

7) La obra de José de Jesús Aguirre: 1 trabajo.

8) La carrera de psicología en la Universidad Nacional de Asunción: 1 trabajo.

Con posterioridad al 2004, el curso de Historia de la Psicología Paraguaya fue propuesto a otras tres instituciones universitarias de Asunción sugiriendo su implementación como seminario complementario en sus carreras de Psicología: a) la Universidad Católica (UCA) en el 2005, b) la Universidad de la Integración de las Américas (UNIDA) en el 2006 y c) la Universidad Autónoma del Paraguay (UAP) en el 2007, aunque sin haber logrado en ninguna de ellas la receptividad necesaria. El camino abierto en la búsqueda de un espacio académico singular donde puedan recrearse la discusión y el estudio de la psicología nacional ha quedado hasta ahora sin nuevos exploradores dispuestos a recorrer su trayectoria.

Antes de concluir la década del 2000 una experiencia más tenía lugar en un escenario académico distinto. En los años 2008 y 2009, los cursos de «Historia de la Psicología I» e «Historia de la Psicología II» que se imparten en el turno de la noche de la Universidad de la Integración de las Américas (UNIDA) y se encontraban a cargo del psicólogo Oscar Sapena mantuvieron un esquema de contenido que otorgó amplio espacio a la discusión de tópicos relacionados con los pioneros locales de la disciplina, a sus obras respectivas y al estudio de textos 
de sistematización que resultaban pertinentes para el conocimiento de esos actores y de los procesos que intervinieron en la configuración de la psicología en el Paraguay. En ocasión del III Congreso Regional de la Sociedad Interamericana de Psicología que se reunió en agosto del 2010 en Asunción (García, 2011d), Sapena (2010) presentó una síntesis de su experiencia didáctica y los propósitos generales que animaron la aplicación de este curso de historia de la psicología nacional. Allí reportaba, a más del texto globalizador de James F. Brennan con el que iniciaba su discusión global en el primer semestre de la materia (Brennan, 1999), la utilización del artículo de Alarcón (2004) sobre la evolución de la psicología latinoamericana a los que acompañaba un nutrido grupo de artículos de temática específica en relación a la historia de la psicología en el Paraguay (García, 2003b, 2005a, 2005b, 2005c, 2006b, 2007). Este proyecto, sin embargo, sufrió algunos efectos negativos que provenían de dificultades originadas al exterior de la cátedra. Al igual que otras instituciones privadas de educación superior en el Paraguay, la UNIDA debió hacer frente a las consecuencias derivadas del exceso de oferta de carreras de Psicología que se registró en los últimos quince años y por ello pudo dar apertura a un semestre inicial por última vez a comienzos del 2009, sin lograr en los llamados a inscripción subsiguientes la convocatoria mínima requerida para permitir el funcionamiento de nuevos grupos de alumnos. Como «Historia de la Psicología» es una materia que se imparte en el primero de los diez semestres que comprende esta carrera, el resultado que acarreó esta dificultad por asimilar nuevos estudiantes es obvia. La persistencia de estos problemas sumados a la falta de un gerenciamiento eficaz para convertir a la carrera en una opción atractiva para la matriculación de nuevos alumnos llevaron al cierre, en apariencia definitivo, a inicios del 2011. La enseñanza de «Historia de la Psicología» ha quedado asî completamente discontinuada y con ello visiblemente trunco el proyecto educativo iniciado en esa cátedra.

\section{COMENTARIOS FINALES}

El camino seguido por aquéllos que iniciaron la enseñanza de la historia de la psicología paraguaya en las aulas universitarias presenta un curso en extremo sinuoso y las actividades resultantes más parecen eventos incidentales y esporádicos que asimilaciones planificadas y consecuentes de nuevos contenidos o áreas de investigación a la estructura formal que define el curriculum formativo de los psicólogos. Pero aún así resultan merecedores de destaque. Y es que fuera de estos exiguos antecedentes no existen otros emprendimientos académicos donde la psicología paraguaya y su detallado análisis histórico hayan tomado el escenario central como temas de enseñanza y estudio. Aunque existen cursos de historia de la psicología general dictados en algunas universidades que incluyen contenidos referidos a la psicología paraguaya, también es forzoso admitir que en la gran mayoría de las cátedras no se hace la mínima mención a la psicología local ni a la disciplina tal como se formó en América Latina. Es por ello que las experiencias impulsadas hasta este momento deben ser justipreciadas en la correcta dimensión que les corresponde. Al mismo tiempo, estos espacios de discusión sirven para 
enumerar algunas presunciones preliminares que podrán confirmarse o descartarse en la medida que nuevos proyectos logren ser desarrollados y sostenidos en la práctica académica y en el diario proceso de la investigación. En base a ellos puede sostenerse lo siguiente:

a) Que la investigación de las psicologías nacionales guarda la relevancia y el interés suficientes para constituir un campo de estudio especializado dentro de la historia general de la psicología.

b) Que los avances particulares de la psicología en el Paraguay a lo largo de los últimos ciento treinta años configuran un amplio conglomerado de temas, aportes teóricos o empíricos y cuestionamientos diversos que reflejan en forma muy precisa las tendencias generadas en la psicología mundial, aunque también conservan el potencial para descubrir e identificar aportes propios.

c) Que la enseñanza de la psicología paraguaya puede recibir un significativo impulso con el desarrollo y consolidación de una producción historiográfica consistente, seria y sistemática.

d) Que la importancia y pertinencia de la enseñanza universitaria de la psicología paraguaya y su historia no constituyen temas de interés y atractivo evidentes ni inmediatos para los estudiantes, pero pueden fundamentarse de manera coherente a través del estudio y la reflexión críticas que se originan en los salones de clase.

e) Que el estudio pormenorizado de la historia de la psicología paraguaya permite a su vez una mejor comprensión de los procesos que generan los cambios en la psicología latinoamericana y universal, al explorar en detalle las particularidades de aquélla psicología nacional y al mismo tiempo resaltar las convergencias y divergencias que mantiene con la ciencia psicológica internacional.

f) Que la enseñanza de la historia de la psicología paraguaya puede conformar un eje integrador muy útil para el avance de la historia de las ciencias sociales en particular o de la historia de la ciencia en general en el Paraguay, teniendo en cuenta la producción muy incipiente que aún representa a estos campos de la actividad intelectual en el país.

No es aventurado suponer que el estudio de la historia de la psicología paraguaya ofrece un conjunto muy significativo de recursos y aplicaciones que se manifiestan en sentidos muy diversos, entre ellos el de estimular el análisis y la visión crítica del estudiante al permitirle una opinión bien informada frente a su propia realidad educativa y científica. Esta nueva perspectiva tiende a conferirle una más fina comprensión sobre los procesos que se hallan involucrados en la evolución de la psicología. Por ello es tan importante desarrollar la capacidad para entender el avance de la disciplina desde el punto de vista de su correcta inserción en cada contexto nacional en particular. Comprender las sutilezas con que la cultura ejerce su influencia sobre la formación de los conceptos científicos, en lo que constituye esa compleja y delicada interelación entre la absorción de las ideas que se originan en espacios foráneos y su asimilación, comprensión, difusión y transformación a través de los conceptos que emergen del entorno ambiental local. Las obras y aportaciones de los psicólogos siempre responden a los dictados de la época, 
a formas de conocer y asimilar el mundo natural y social que son compartidos por comunidades de científicos o de practicantes, a necesidades urgentes que se deben atender en cualquier grupo humano y a ideales sociales, educativos y personales que pueden ser compartidos o cuestionados desde la atalaya que brinda la psicología. La historia es el marco de fondo contra el que resalta lo más esencial de las producciones intelectuales de los individuos y los grupos comunitarios a los que pertenecen. Es el escenario donde se representan los dilemas que enfrenta la sociedad en su conjunto o las aspiraciones hacia las que busca trascender colectivamente a cada momento. Por eso la ciencia, por muy abstracta y atemporal que pueda parecer a los observadores incautos en el lenguaje de sus formulaciones generales, surge -cuando es creada- o se asimila -cuando es aprendida- dentro de los contornos que define una sociedad concreta.

La evolución histórica de la psicología participa de estas mismas condiciones que acompañan a la ciencia en general y se perciben sobre todo en las transformaciones que regularmente sufren su objeto de estudio y sus metodologías de investigación. Es por ello que el análisis intensivo de las psicologías nacionales contribuye a esta clarificación de los mecanismos que generan la aparición de nuevas ideas, así como el surgimiento de cuestionamientos dirigidos desde el trabajo individual de los investigadores hacia el marco conceptual de la ciencia. Resultan muy importantes la asimilación de conceptos y teorías que son traducidos desde sus proposiciones más universales para adaptarlos, corroborarlos o refutarlos en el contexto local. A fin de cuentas, este es el que de verdad importa, ya que en el habitan las personas concretas hacia las que el psicólogo -en especial el profesional aplicado- está llamado a dar respuestas creativas. Pero también ese contexto local es el ámbito donde opera el investigador científico, cuya acción se manifiesta cuando evalúa la generalidad de las teorías o persigue las manifestaciones particulares de estas en los fenómenos del comportamiento, descubriendo así los aspectos que no pueden ser explicados o predichos adecuadamente por las teorías en uso. El estudio de la psicología en su vertiente temporal comprime todos estos aspectos. La historia de las psicologías nacionales, con el análisis de sus obras y producciones, es una forma de ver la psicología universal desde el interior de cada realidad local y de comprender, mediante su estudio y discusión, el valor que adquiere lo particular en el avance de cualquier campo del conocimiento científico. Al mismo tiempo, y por obra de idéntico mecanismo comparativo, contribuye a calibrar la fuerza que ejerce lo universal cuando se encuentra presente en el trabajo de cada investigador. Es así como la historia renueva su fundamental carácter de vigía para la configuración del saber humano y en la celosa preservación de la verdad.

\section{REFERENCIAS BIBLIOGRAFICAS}

Aguilar, G. y Recinos, L. A. (1996). Historia y estado actual de la psicología en Guatemala. Revista Latinoamericana de Psicología, 28, 197-232.

Aguilera, C., Benítez, C. y González, J. (1998). Adecuación curricular. Carrera: Sicología con énfasis en Orientación Educacional. Universidad Nacional de Pilar, Facultad de 
Humanidades y Ciencias de la Educación. Documento no publicado.

Alarcón, R. (1980). Desarrollo y estado actual de la psicología en el Perú. Revista Latinoamericana de Psicología, 12, 205-235.

Alarcón, R. (2004). Medio siglo de psicología latinoamericana: Una visión de conjunto. Revista Interamericana de Psicología, 38 (2), 307-316.

Alarcón, R. (2010). El legado psicológico de Rogelio Díaz-Guerrero. Estudos e Pesquisas em Psicologia, 10 (2), 553-571. http://www.revipsi.uerj.br/v10n2/artigos/pdf/ v10n2a16.pdf

Alonso, M. (2007). Psicología en el Paraguay. Presentación en formato de power point.

Anónimo (1967). Crónica interna. Dimensión. Páginas Universitarias, 5 (17), 9.

Ardila, R. (1986). La Psicología en América Latina. Pasado, presente y futuro. México: Siglo XXI.

Ardila, R. (1997). Hacia el próximo milenio: psicología, ciencia y sociedad. El papel de la síntesis experimental del comportamiento. Revista Latinoamericana de Psicología, 29, 495-503.

Ardila, R. (2003). La necesidad de unificar la psicología: El paradigma de la síntesis experimental del comportamiento. Revista Colombiana de Psicología, 12, 28-37.

Brennan, J. F. (1999). Historia y sistemas de la psicología. México DF: Prentice-Hall, Quinta edición.

Caparrós, A. (1990). Historia de la Psicología. Barcelona: Ediciones CEAC, 4ta. Edición.

Cardozo, R. I. (1938). La pedagogía de la escuela activa. Tomo I: Psicología de la escuela activa o fundamentos psico-pedagógicos. Asunción: Edición del autor.

Colazo, C. (1993). Los partidos políticos en el Paraguay. Estructura interna. Asunción: CIDSEP.

Díaz-Guerrero, R. (1995). Una aproximación científica a la etnopsicología. Revista Latinoamericana de Psicología, 27, 359-389.

Dorsch, F. (1994). Diccionario de Psicología. Barcelona: Herder.

García, J. E. (2003a). Origens da Psicología Social no Paraguai. En A. M. Jacó-Vilela, M. Lopes da Rocha y D. Mancebo (Orgs.), Psicologia Social. Relatos na América Latina (pp. 85-122). Sâo Paulo: Casa do Psicologo.

García, J. E. (2003b). Ramón Indalecio Cardozo y la difusión inicial de las ideas de Sigmund Freud en el Paraguay. Teoría e Investigación en Psicología, 11 (2), 273-318.

García, J. E. (2004). La evolución de la Psicología en el Paraguay: Una evaluación desde el modelo de Hiroshi Azuma. Revista Intercontinental de Psicología y Educación, Segunda Epoca, 6 (2), 25-36.

García, J. E. (2005a). Historia e Historiografía de la Psicología en el Paraguay. En J. R. Vivas (Ed.), Las Ciencias del Comportamiento en los albores del Siglo XXI (pp. 286-290). Mar del Plata: Editorial Universidad Nacional de Mar del Plata. 
García, J. E. (2005b). Psicología, Investigación y Ciencia en el Paraguay: Características resaltantes en el periodo preuniversitario. Revista Interamericana de Psicología, 39 (2), 305-312.

García, J. E. (2005c). El joven Eusebio Ayala y la psicología paraguaya. Teoría e Investigación en Psicología, 14, 46-90.

García, J. E. (2006a). Publicaciones paraguayas en el área de la psicología: 1960-2005. Revista Latinoamericana de Psicología, 38 (1), 149-167.

García, J. E. (2006b). Relaciones históricas entre la psicología y la educación en Paraguay. Psicologia da Educaçâo, 22, 95-137.

García, J. E. (2007). La psicología en Paraguay y el problema de la determinación de los pioneros. Revista Intercontinental de Psicología y Educación, Tercera Epoca, 9 (2), 113-146.

García, J. E. (2008a). Ramón Indalecio Cardozo como pionero de la psicología en el Paraguay. Revista Interamericana de Psicología, 42 (1), 171-180.

García, J. E. (2008b). Manuel Riquelme y la historia de la psicología. Fundamentos en Humanidades, 9 (2), $N^{o} 18,25-54$.

García, J. E. (2009). Breve historia de la psicología en Paraguay. Psicología para América Latina, $N^{o}$ 17, Agosto 2009. http://www.psicolatina.org.

García, J. E. (2010a). La enseñanza de la psicología en la Universidad Nacional de Asunción (Paraguay). Teoría e Investigación en Psicología, 19, 61-179.

García, J. E. (2010b). Ramón Indalecio Cardozo y su contribución a la psicología infantil. Boletín de la Fundación «En Alianza», Año 17, N ${ }^{o}$ 52, 10-13 [e/7].

García, J. E. (2011a). Fundamentos y objetivos para la enseñanza de la historia de la psicología paraguaya. Pensamiento Psicológico. En prensa.

García, J. E. (2011b). Historia y estado actual de la Psicología en la ciudad de Encarnación, Paraguay. Manuscrito sometido a publicación.

García, J. E. (2011c). Ramón Indalecio Cardozo: Entre la Psicología, la Pedagogía y la praxis social. Manuscrito sometido a publicación.

García, J. E. (2011d). La Sociedad Interamericana de Psicología (SIP) y sus relaciones con la psicología paraguaya. Manuscrito sometido a publicación.

Hoffman, M. H., Tortosa, F. y Carbonell Vaya, E. (1994). Emilio Mira y López y el desarrollo de la psicología del tráfico. Los casos de España y Brasil. Revista Latinoamericana de Psicología, 26, 495-516.

Klappenbach, H. A. y Pavesi, P. (1994). Una historia de la psicología en Latinoamérica. Revista Latinoamericana de Psicología, 26, 445-482.

León, R. (1993). Contribuciones a la historia de la psicología en el Perú. Lima: CONCYTEC.

León, R. (1997). Rumbo al nuevo mundo: Cuatro psicólogos de Europa Oriental en la historia de la psicología en América del Sur. Revista Latinoamericana de Psicología, 
29, 9-34.

Mullin, C. (1964). El Cosmos y Dios. Las ciencias experimentales y las pruebas de la existencia de Dios. Universidad Católica, Facultad de Filosofía y Ciencias de la Educación. Tesis de Doctorado no publicada.

Papini, M. R. (1978). La psicología experimental argentina durante el periodo 1930-1955. Revista Latinoamericana de Psicología, 10, 227-258.

Papini, M. R. (1988). Influence of evolutionary biology in the early development of experimental psychology in Argentina (1891-1930). International Journal of Comparative Psychology, 2, 131-138.

Papini, M. R. y Mustaca, A. E. (1979). La psicología experimental argentina entre 1956 y 1978. Revista Latinoamericana de Psicología, 11, 349-361.

Riquelme, M. (1948). Lecciones de Psicología. Buenos Aires: Angel Estrada Editores, novena ed. (edición original 1936).

Rivelli, D., Lafuente, C. L. y Lafuente, M. J. (1994). Diseño curricular de la carrera de Psicología. Universidad Católica de Ciudad del Este. Propuesta del curriculum formal. Universidad Católica, Documento no publicado.

Sapena, O. (2010). La historia de la psicología en Paraguay: Una experiencia de enseñanza. Trabajo presentado en el simposio Procesos modeladores en la historia de la psicología latinoamericana, coordinado por José E. García. III Congreso Regional de la Sociedad Interamericana de Psicología. 4 al 6 de agosto del 2010. Asunción, Paraguay.

Sosa Costantini, E. (1974). Reflexología. La raíz histórica de la reflexología. Asunción: Edición del autor.

Székely, B. (1966). Los tests. Manual de técnicas de exploración psicológica. Buenos Aires: Kapelusz (Quinta edición. Edición original: 1946). 


\author{
ANEXOS \\ ANEXO NÚMERO 1. \\ Lista de investigaciones producidas en el \\ Seminario «Introducción a la psicología paraguaya» \\ Primera parte: «Historia de la psicología en el Paraguay» de la \\ Universidad del Norte (Asunción) durante el año 2004.
}

1. Alfonso, Miguel Angel; Acha, Jorge Adrián y Benítez, Hugo: La psicología latinoamericana.

2. Argañaráz, Yilse; Acuña, Christian y Mohtadi, Marllam; Carrera de Psicología en la Universidad Nacional de Asunción (UNA), sus campos de desempeño y los contenidos que se han venido desarrollando en cada uno de sus cursos.

3. Cardozo Román, María: Cecilio Báez y Ramón I. Cardozo.

4. Galeano, Rosa; Santos, Montserrath y Colmán, José: Historia de la psicología latinoamericana

5. Laneri, María Angélica; Gomes, Zélia y González, Elena: José de Jesús Aguirre.

6. Narváez, Alexis: Andrés Rivarola Queirolo.

7. Olmedo, Griselda y Hermosilla, Wilma: La psicología indígena.

8. Ruíz, Sara; Aguilera, Carmen y Díaz, Leticia: Orígenes de la psicología en el Paraguay.

9. Souza Benitez, Rosiane de: La Revista del Instituto Paraguayo.

10. Vásquez, Iris y Benítez, Luz: El hipnotismo de Diógenes Decoud. 


\author{
ANEXO NÚMERO 2. \\ Contenidos programáticos incluidos en el \\ Seminario «Introducción a la psicología paraguaya», \\ Primera parte: «Historia de la psicología en el Paraguay» de la \\ Universidad del Norte (Asunción) \\ Durante el año 2004.
}

\title{
I. LA PSICOLOGIA LATINOAMERICANA.
}

- Orígenes de la Psicología en América Latina.

- La ciencia, la academia y la profesión.

- El presente y el futuro.

\section{ORIGENES DE LA PSICOLOGIA EN EL PARAGUAY.}

- La escolástica colonial.

- Los comienzos de la enseñanza de la Psicología en el Colegio Nacional y en la formación de los maestros.

- Diógenes Decoud: La medicina y el hipnotismo.

\section{LAS REVISTAS CULTURALES Y UNIVERSITARIAS.}

- El Instituto Paraguayo y su Revista.

- ¿Primeros artículos psicológicos?

- Repaso de las publicaciones de contenido psicológico en la Revista del Instituto Paraguayo.

\section{MANUEL DOMINGUEZ.}

- Contexto cultural e histórico.

- Las ideas de Manuel Domínguez sobre el carácter nacional.

- El paraguayo, la influencia de la raza y de los factores ambientales.

\section{LA PSICOLOGIA SOCIAL Y LA SOCIOLOGIA.}

- Positivismo y Evolucionismo en el Paraguay.

- La psicología social de Cecilio Báez.

- La psicología social de Ignacio A. Pane. 


\section{LA PSICOLOGIA DE EUSEBIO AYALA.}

- La vida y la obra de Eusebio Ayala.

- Eusebio Ayala en los Anales de la Universidad Nacional de Asunción: Los problemas de la sensación y la perceptividad.

- Otras contribuciones de Ayala.

\section{LA PSICOLOGIA Y LA EDUCACION (I).}

- El evolucionismo lamarckiano de Fernando Tapia.

- Las ideas psicológicas de Juan Ramón Dahlquist.

- María Felicidad González y la Paidología.

\section{RAMON INDALECIO CARDOZO (I).}

- Contexto cultural e histórico.

- La introducción de la Escuela Activa.

- Las ideas de Freud según Cardozo.

\section{RAMON INDALECIO CARDOZO (II).}

- Las primeras experiencias con la aplicación del test Stanford-Binet en el Paraguay.

- El monismo energetista de Cardozo.

- La psicología de la Escuela Activa.

\section{LA PSICOLOGIA Y LA EDUCACION (II).}

- La Psicología de Manuel Riquelme.

- Emilio Uzcátegui y la fundación del primer laboratorio psicológico paraguayo.

- Importancia y contribución de los educadores al desarrollo de la Psicología.

XI. EL PERIODO UNIVERSITARIO.

- La fundación de las primeras carreras de Psicología.

- La expansión universitaria de los años noventa y los desafíos que presenta.

- La Psicología Aplicada en el Paraguay.

\section{JOSE DE JESUS AGUIRRE Y MERARDO ARRIOLA-SOCOL.}

- Aguirre y los estudios tipológicos del hombre paraguayo.

- Una psicología de tinte espiritualista.

- Merardo Arriola y el aprendizaje significativo. 
La Enseñanza de la Historia de la Psicologia en las Universidades Paraguayas

\section{REALIDAD Y LIMITACIONES ACTUALES.}

- Los problemas en la formación académica.

- Publicaciones psicológicas en el Paraguay.

- Conclusión: Las tendencias de la Psicología paraguaya en el futuro inmediato. 